\title{
Breast cancer in men
}

\author{
Wesley D. Block MD PhD, Derek Muradali MD
}

\section{More men die from breast cancer than from testicular cancer}

Of the 9355 men diagnosed with breast cancer in the United States from 2004 to 2008 , there were 1934 deaths, compared with 1758 deaths from 39641 cases of testicular cancer. ${ }^{1}$

Male breast cancer usually presents with a palpable subareolar mass

Although the most common cause of a breast mass in men is gynecomastia, $75 \%$ of cases of male breast cancer present with a palpable subareolar mass. ${ }^{2.4}$ Less common features include ulceration, nipple retraction or discharge, pain and axillary adenopathy. ${ }^{2}$

Men with breast cancer experience symptoms for an average of 6 months before the diagnosis is made $^{2}$

Breast cancer in men presents at more advanced stages than in women, with $38 \%$ of men having axillary nodal involvement compared with $29 \%$ of women. ${ }^{5}$ The stage- and age-adjusted 5year survival rates for men and women are similar, but comorbidities in older men lead to worse prognosis. ${ }^{5}$

\section{Male carriers of the BRCA2 mutation have an 80 -fold increased lifetime risk} of breast cancer

Although male carriers of the BRCA2 mutation have a markedly increased risk of breast cancer, the estimated lifetime risk in the general population of men is $0.1 \%{ }^{2}$ Risk factors for male breast cancer include family history, gene mutations (BRCA2, $B R C A 1)$, age, Klinefelter syndrome, chest radiation and altered testosteroneestrogen levels (e.g., due to liver cirrhosis, gonad dysfunction, estrogen use, obesity). ${ }^{2}$

Screening recommendations for men with a strong family history, genetic predisposition or history of breast cancer include monthly self-examination, semiannual clinical examination (starting at age 35) and baseline mammography (at age 40) with further annual mammography if increased breast density is seen on a baseline mammogram. ${ }^{3}$ No screening guidelines exist for men in the general population.
Palpable breast masses in men require mammography and possible biopsy

In one study, mammography had a sensitivity of $92 \%$ and specificity of $90 \%$ for male breast cancer $(n=$ 104). ${ }^{6}$ A spiculated or irregular mass (with or without calcification) is the typical mammographic appearance. Breast ultrasonography can confirm the presence of a suspicious mass and facilitate ultrasound-guided biopsy. Biopsy is recommended for all suspicious masses. ${ }^{2}$ Histology shows infiltrating ductal cancer in $90 \%$ of cases. ${ }^{2}$
$C M A J$ invites submissions to "Five things to know about ..." Submit manuscripts online at http://mc.manuscriptcentral.com/cmaj

\section{References}

1. US Cancer Statistics Working Group. United States cancer statistics: 1999-2008 incidence and mortality web-based report. Atlanta (GA): US Department of Health and Human Services, Centers for Disease Control and Prevention and National Cancer Institute; 2012. Available: http://apps.nccd.cdc .gov/uscs/ (accessed 2012 Dec. 21).

2. Fentiman IS, Fourquet A, Hortobagyi GN. Male breast cancer. Lancet 2006;367:595-604.

3. NCCN clinical practice guidelines in oncology. Breast cancer screening and diagnosis (version 1.2012). Fort Washington (PA): National Comprehensive Cancer Network; 2012. Available: www .nccn.org/professionals/physician_gls/f_guidelines .asp (accessed 2012 Dec. 21).

4. Volpe CM, Raffetto JD, Collure DW, et al. Unilateral male breast masses: cancer risk and their evaluation and management. Am Surg 1999;65:250-3.

5. Giordano SH, Cohen DS, Buzdar AU, et al. Breast carcinoma in men: a population based study. Cancer 2004;101:51-7.

6. Evans GF, Anthony T, Turnage RH, et al. The diagnostic accurancy of mammography in the evaluation of the male breast. Am J Surg 2001;181:96-100.

Competing interests: None declared.

This article has been peer reviewed.

Affiliations: Department of Medical Imaging (Block), Faculty of Medicine, University of Toronto; Department of Medical Imaging (Muradali), St. Michael's Hospital, Toronto, Ont.

Correspondence to: Wesley D. Block, wesley.d .block@gmail.com

CMAJ 2013. DOI:10.1503/cmaj.122056 